\title{
A COMPREHENSIVE AND PARTICIPATORY APPROACH TO THE VALORISATION OF BIODIVERSE PRODUCTS
}

\author{
Gianluca Brunori, Adanella Rossi, Simona D’Amico \\ University of Pisa \\ gianluca.brunori@unipi.it
}

\begin{abstract}
Preserving agro-biodiversity can contribute to the broader goal of protecting and enhancing biodiversity. Acknowledging and managing the complexity of values connected to agro-biodiversity, translating them in coherent practices, is the key to its conservation and valorisation. These processes may take place at different stages of agro-biodiversity management and interact with other factors, dynamics and processes that intervene in it.

This study presents the EU funded DIVERSIFOOD project as an exemplification of the comprehensive approach that is needed to effectively preserve and enhance agro-biodiversity. The main objective of the project is to deepen the factors and processes of various nature that can support the reintroduction of biodiversity in cropping systems, improve its management and promote a social and economic valorisation of final food products. To that end, the project explores the processes underlying the re-shaping of practices according to the objective of agro-biodiversity enhancement in all the stages of the food chain.

The need to take into consideration the different perspectives on values and ways of preserving agro-biodiversity, together with the development of new shared knowledge and practices underlies the adoption of participatory, multi-actors approaches to each of these stages. Similarly, an inter-disciplinary approach, aimed at combining natural sciences and social sciences characterises the work of researchers.
\end{abstract}

\section{Keywords}

Agro-biodiversity, biodiverse food products, participatory approaches, multi-actor approaches, integrated approaches, inter-disciplinarity

\section{INTRODUCTION}

The loss of biodiversity is currently underway and it has intensified over the past twenty years. The loss of biological diversity is the result of a combination of 
anthropological and ecological interrelated factors (Ash and Fazel, 2007; Mayes et al., 2011). Studies mention habitat conversion, invasive alien species, resources overexploitation, climate change and pollution among the causes of species diversity reduction. Moreover, these factors are likely to be behind the contraction, or even homogenisation, of species variety, since they bring with them other environmental damage to ecosystems (Pimentel et al., 1992; Ash and Fazel, 2007; Mayes et al., 2011).

Agriculture has historically had the largest impact on biodiversity, and it is expected to continue to be a factor of biodiversity loss in the future (OECD, 2008). The way food production and consumption are organized in the mainstream industrial food system is indeed responsible of a high pressure on natural resources. This system has been relying on agricultural intensification, which has implied the conversion to predominantly monoculture farming of lands with an original high biodiversity value, and on the production of few major crops and staples ${ }^{1}$, neglecting the diversity of traditional, place-specific, crops (GTZ, 2002; Guère et al., 2006; ICUC, 2006; Padulosi et al., 2013). The intensive usage of resources by a growing human population will further exacerbate these negative dynamics (Ash and Fazel, 2007).

Besides reducing biological diversity this model has also undermined cultural diversity because of the shrinking space left to traditional methods of crops improvement, farming and food traditions that are rooted in specific cultural contexts (Ceccarelli and Grando, 2007; Morris et al., 2004; Johns et al., 2013).

The transition to sustainable farming systems may contribute to the protection and enhancement of biodiversity, through the diversification of species and varieties in the productive cycles and the provision of agro-ecosystem services. Preserving agrobiodiversity, however, appears as a complex problem that requires systemic intervention. The particular and diverse nature of values involved in the conservation of agro-biodiversity and the complexity of the processes that underlie it demand to address the issue from different perspectives - technical, but also cultural, social and economic, as well as legal and political. There is the need for significant changes in the way of managing genetic resources and production activities, in the capacity of recognising and appreciating the values embodied in the final products, and in the role of institutional and political environment. Going deeper, this involves deepening the processes underlying the biodiversity value perception and the development of coherent practices, looking at the related enabling and hampering factors.

All this has significant implications for the definition of the approaches to the management of this issue, in all areas of intervention. This is particularly evident for the

\footnotetext{
${ }^{1}$ Historically, humans have exploited thousands of plant species for food; today, however, most people on Earth depend on 20 types of plants and three staple crops (rice, wheat, and corn) (Leverty and Sterling, 2003).
} 
research, as shown by the recent EU funded project DIVERSIFOOD ${ }^{2}$, aimed at studying the factors underlying the consolidation and market valorisation of biodiverse food. This contribution draws on the experience gained in this project, considering it as a useful exemplification of the comprehensive and integrated approach that is needed.

\section{PRESERVING AND ENHANCING AGRO-BIODIVERSITY}

Acknowledging and managing the complexity of values connected to agrobiodiversity, translating them in coherent practices, are the key to its conservation and valorisation. These processes may take place at different stages of agro-biodiversity management and interact with other factors, dynamics and processes that intervene in it. After the illustration of the different values encompassed in (agro-)biodiversity and their role for the main actors involved, this section deals with: the role of the cultural and social dynamics; the meaning and implications of the different approaches to agrobiodiversity management, with reference to stakeholder involvement; the significance of strategies of market valorisation of biodiverse products, as specific space of alignment and coherence building amongst the several actors involved; the role of political frameworks within which interventions to maintain and enhance agro-biodiversity developed.

\section{Building and recognizing values of biodiversity}

Through its various components, biodiversity provides different goods and services; these, in their turns, offer different benefits - ecological, economic, sociocultural -, not always easy to distinguish and to evaluate. Furthermore, biodiversity assumes the form of a public or of an open access good; in both of the cases market has proved to be inefficient. In the first case, normal market process has for a long time failed to catch the values of some, or all, aspects connected to biodiversity, so not showing its scarcity. In the second case, the benefits of biodiversity are realised as private benefits, whereas the associated costs of using biodiversity resources are shared as social or public costs (Government of Ireland, 2008).

All this complicates the process of preserving and enhancing biodiversity. However, the need to assign a value to biodiversity has grown, hand in hand with the necessity to face the issue of biodiversity increasing reduction through adequate measures and actions. Some studies identify two main kinds of biodiversity values: intrinsic values, which are inherent to biodiversity, to the right to exist of the life forms on which biodiversity builds up; extrinsic values, which grow out of the uses or

\footnotetext{
2 DIVERSIFOOD is a four-years project funded by the European Union within the Horizon 2020 Programme (Grant Agreement no 633571). It involves 21 partners, belonging to 12 countries. The partners are public and private research institutes and various organizations engaged at regional level on issues of conservation and enhancement of agro-biodiversity. See: www.diversifood.eu.
} 
applications of the life forms constituting biodiversity (Alho, 2008; Leverty and Sterling, 2003). Another consolidated taxonomy, adopted in environmental economics (Turner et al., 1994), resolves the overall economic value of biodiversity into a set of values (OECD, 2002). The first important distinction is between use values and non-use values. The first derive from the use that people make of goods and services that can be considered as the by-products of biodiversity. They are distinguished in direct and indirect use values. The former imply consumption of resources and are associated to market prices; they refer to goods, such as food, fibbers, fuel, or medicines. The latter do not imply consumption of resources and are characterised by a greater difficulty in evaluation; they are linked to services that mainly refer to the ecosystem services granted by the existence of biodiversity, such as soil and water conservation, pollination, nutrient cycling, aesthetic components, recreation and other. A particular form of the use value is the option value that refers to the possibility of a future use of the resources, allowed by a current conservative management ${ }^{3}$. The non-use values refer to not utilitarian values. They encompass the existence value and the bequest value. The former is the intrinsic value recognized to the life forms constituting biodiversity, to the mere existence of a wide range of genetic resources, regardless the possibility of their use; the latter is the value attributed to the future societies chance to make use of the resources, according to intergenerational equity principles.

The different stakeholders involved in processes of biodiversity preservation may perceive these values differently and so may give different importance and attach different meanings to them (Leverty and Sterling, 2003).

What described so far with respect to the value of biodiversity holds in the context of agro-biodiversity too. The value of agro-biodiversity expresses in different forms, which, although not all or not fully or easily translatable into economic value, all are crucial to the appreciation of agro-biodiversity by the different actors who play a role in the food system. They include actors involved in all the stages of the food chain, from breeders to consumers as well as researchers and policy makers. In the case of farmers, use value of agro-biodiversity may refer to direct benefits, when the specific genetic resources allow creating a differentiated offer on the market, and also to the functional benefits deriving from the greater resilience of the agro-ecosystems, which may have an effect in economic terms too. In the case of consumers, this value expresses in the opportunity to meet dietary needs (such as nutritional and health-related needs) or to enjoy sensorial or hedonistic benefits, according to the peculiarities of biodiverse products. Consumers also benefit of indirect use value, as in the case of utilization of recreational or educational services provided by agro-tourism. More in general, indirect use value relates to the wider positive effects stemming from

\footnotetext{
${ }^{3}$ It is the case of resources whose value has been untapped yet but can emerge from further research and experiences.
} 
production systems and products building on biodiversity. These may include the benefits to society due to the greater resilience of the agro-ecosystems (which, in its turn, may translate in future use values by guaranteeing, for instance, food/environment conservation). At local level, they may include the benefits stemming from the inclusion of these products in broader programs of valorisation of territorial capital (as in the case of many rural development projects). With regard to non-use value, the role that

agriculture may play in conserving and managing biodiversity is recognised by growing segments of society. Within them, concerned consumers reward this role also through their consumption choices.

\section{The role of cultural and social dynamics}

As said above, the acknowledgment of agro-biodiversity values is crucial to their production, management and enjoyment.

As more in general for biodiversity values, going from direct use values, through indirect use values, to potential or intrinsic values (as bequest and existence values) the tangibility of benefits and furthermore the possibility of their conversion into economic value decrease. Most of these values are expression of a less utilitarian and anthropocentric attitude, which relates to cultural and ethical value systems. These values may however be important in affecting the production and consumption choices and, more generally, decisions related to its management.

The importance attached to the (need for conservation of) agro-biodiversity is so closely dependent on the understanding of the interactions between biodiversity and the societal life conditions and, however, on the importance individually/socially assigned to the extrinsic and intrinsic values of biodiversity.

The relevance of the cultural determinants emerges also considering the role of knowledge, culture and skills in the handling of genetic resources (e.g. in farming and processing activities) and in the enjoyment of benefits stemming from biodiversity (e.g. product quality or aesthetic values of landscape in consuming activities). The process of co-evolution between the two systems makes this link even more meaningful. The evolutionary adaptation of ecological biodiversity and of the knowledge that is needed for its management go in fact together. The same is for the capacity to appreciate the values of the biodiverse food or the biodiverse natural environment. The decrease of genetic resources leads to the decrease of cultivation adaptability to the environment, but also implies a loss of knowledge of their use and management, in a sort of 'coinvolution'. Furthermore, this affects the potential values of biodiversity (option and bequest values) twofold, as it loses most of its significance with the loss of human capabilities to use the genetic resources.

All this confirms how central is the issue of culture in the conservation and 
reproduction of (agro-)biodiversity (Mathez-Stiefel et al., 2009). It is evident, on the other hand, that these culturally mediated processes are dependent on the characteristics of the specific socio-economic contexts: the ways of looking at biodiversity, of grasping its values, of understanding the related problems and the need for solutions vary according to the cultural models and social organizations (Nuijten et al., 2013; Johns et al., 2013).

In that regard, the contexts where the development of the agro-food system has led to the simplification of both agro-ecosystems and human diets need a relevant effort to recover knowledge and skills, both from the side of the producers and from that of consumers. Farmers need not only to adapt the farming activities but also to reorganize their relational network, to find new opportunities to exchange and share information. In most of the cases, taking responsibility of the management of agro-biodiversity also implies a real change of identity, not only to leave the model of modern, specialized farmer, but also to move from a socially recognized and often economically rewarded role of conservation, to an active, community-based engagement in recovering and improving biodiversity. This process involves a considerable cultural shift. For consumers the needed changes in terms of sensitivity, preferences and practices is not less demanding, because of the more mediated relationship with natural resources. The growth of knowledge about the existence and properties of other species/varieties compared to the few usually marketed and the change of dietary habits are the first step to any initiative of conservation and valorisation of agro-biodiversity. Positioning this agro-biodiversity in the specific territorial contexts and identifying the specific production systems that manage it represent a further significant step. This connection is what has characterized the preference accorded to the typical and traditional food products and has frequently represented the central element of rural development projects. With an even greater emphasis on the relational dimension of the recognition of the product value, more recently it is what underlies the development of localized circuits of production-consumption and the related community-based engagement for biodiversity enhancement (Brunori et al., 2011; Simoncini, 2015).

In other contexts, as those of developing countries, where the pool of knowledge linked to agro-biodiversity has been eroded less because of the survival of the traditional farming systems and dietary habits, the challenge is to create the conditions to preserve and enhance it while trying to consolidate or improve food systems (Johns et al., 2013). Here the role of cultural aspects, linked to social components and, in general, strongly context-dependent, is even more complex. They may include, for instance, gender, age, identity, cultural tradition, religious and ethnic or political conflict issues. These factors deeply shape the relationship with and the evolution of technologies (varieties, tools, techniques) that are significant to agro-biodiversity management (Nuijten et al., 2013). The interdependencies of cultural and biological diversity and the need to enhance socio-cultural processes in order to foster agro-biodiversity is at the 
basis of the "biocultural approach" of some regional development programs (MathezStiefel, 2009). On the other hand, for the same interdependence, enhancing the use of specific genetic resources is seen as a means to keep food traditions, cultural values and community and social identities (Johns and Eyzaguirre 2002; Padulosi and Frison, 1999).

All this points out the importance to work on the deep mechanisms underlying the cultural and social mediators of agro-biodiversity management. In that regard, learning processes that develop in the specific social environments and relational spaces are certainly to be explored.

\section{The approach to the agro-biodiversity management}

The development of learning processes and through them of new attitudes, knowledge and practices around agro-biodiversity management is closely linked to the degree of actors' involvement. This especially concerns farmers and consumers, for a long time not directly and actively engaged in managing agro-biodiversity.

In this regard, it is particularly meaningful the difference between the conventional approach to genetic improvement and the alternative approaches that have developed around the objective to tackle agro-biodiversity-related problems.

The conventional approach to crop improvement has been traditionally guided by the aim of meeting agro-industry needs in terms of crop stability, adaptability to a wide range of environments and high productivity (both of them relying on intensive use of chemicals), as well as wide acceptance of the related final products. Hence, this approach is effective when operating in uniform and stable environments and at the expense of biological and cultural diversity. Furthermore, it does not need much autonomy by farmers, but rather relies on control of know-out and a well organised marketing of reproductive material and related needed inputs.

The willing to overcome the limitations of this approach has led to seek a closer relationship with environmental, biological and cultural specificities of contexts. To that end, Participatory Crop Improvement (PCI) aims at linking the conventional, globalized crop improvement approach with localized and culture specific ones. It seeks combining productivity and cost-effectiveness with maintenance and enhancement of agrobiodiversity and cultural diversity (Hardon, 1995). The PCI-strategy is twofold: on one side, it inserts huge genetic diversity into the local farming systems; on the other, it relies on farmers' capacity to select, conserve, re-produce and exchange seeds that prove to be particularly suitable to the specific environment and to the local farming and food traditions (Almekinders and Elings, 2001).

Central to these approaches is evidently the direct involvement of farmers in the various stages of agro-biodiversity management. PCI includes Participatory Variety Selection (PVS), Participatory Plant Breeding (PPB) and in-situ conservation of crops. 
PVS involves farmers and other stakeholders along the food chain together with researchers in the selection of varieties from formal and farmer-based collections and trials. The selection criteria give particular importance to the suitability of the varieties to local agro-ecosystems as well as to needs, uses and preferences of the involved stakeholders. PPB sees the same approach applied to the different plant breeding stages of the process of plant breeding. Finally, in-situ conservation is a strategy for crops conservation that relies on farmers taking up, growing and exchanging seeds. It generates genetic varieties that, while being common in certain ecological and cultural environments, may be absent from conventional seed bank catalogues (the ex-situ conservation) (Almekinders and Elings, 2001).

PCI has been spreading in marginal and changing ecological environments of developing countries where small and traditional - sometime subsistence - farming is predominant. In these contexts, PCI worked to compensate the ineffectiveness of conventional crop improvement approaches (Tripp, 1997). Its more suitable approach relies on the use of locally adapted genetic resources and learning from traditional knowledge to deal with environmental variation and production risks (Clawson, 1985; Brouwer et al., 1993; Van Noordwijk et al., 1994). Furthermore, in some experiences, special attention is given to gender issues. The involvement of women is prioritized for their relevant but also specific role in farming. Involving women is seen as a way to consider broader verities of seeds, breeding, farming and conservation techniques that may be suitable to as much broader cultural and ecological environments (Farnworth and Jiggins, 2003).

Hence, PCI results in valorising biological and cultural diversity as well as in empowering rural communities, while responding to the needs of traditional farming systems in marginal environments. However, its positive impact highly depends on how it is implemented. In this regard, the degree of genetic diversity used and the level of involvement of farmers and other local stakeholders, besides scientists, are crucial (Morris et al., 2004).

More recently, PCI has been adopted also in developed countries, where it again represents an alternative approach to the practices supported by the mainstream scientific and agro-industrial system. Also in this case it makes reference to the guiding principles of reintroducing genetic variety in farming systems, by valorising the specific characteristics of local environments and the knowledge, skills and preferences of farmers and other stakeholders, with respect to the conventional powerful role of scientists and input-industry agents.

In these contexts, the participatory involvement of farmers and the other chain agents is even more significant, because of the force of the hegemonic culture that informs any aspects of technology of farming and processing stages and of the loss of autonomy, decision power, knowledge and skills that has interested their actors over the modernization of agro-food system. We have already mentioned these aspects dealing 
with cultural factors. Likewise, the involvement of users and final consumers radically changes the condition in which they usually play their role, generally passive and disadvantage in terms of knowledge, skills and decision power. In this regard, there is an increasing attention to the opportunities stemming from processes of 'value coproduction' (Krucken, 2005). In both of the cases, it thus emerges how the engagement of these stakeholders in the process of production, management and enjoyment of biodiversity is not just a matter of rights, but also implies the existence of enabling conditions for its actualization.

\section{The potential of market valorisation of biodiverse food}

The conservation and enhancement of biodiversity finds important opportunities in the market valorisation of the final products ${ }^{4}$. The appreciation of these products on the market may generate income for the chain actors and indirectly for other actors involved, and at the same time spread further knowledge about the existence and properties of the products. In both of the cases, it may contribute to the maintenance of the production systems and the related environmental and social benefits. Furthermore, a market valorisation of these products may play an important role in broader strategies of enhancement and promotion of territorial resources, favouring the creation of synergies among different sectors.

This economic valorisation assumes specific characters in different socioeconomic contexts.

In developing countries, structuring the marketing of these products, by the creation of proper value chains, is considered a way to overcome the limitations due to the subsistence level of farming or the scant knowledge out of the local contexts of production-utilization or, in general, logistic difficulties. This may increase social welfare by generating income opportunities and new small economies (Will, 2008; ICUC, 2006). It may also be seen as the needed condition to broaden the commercialization of the products in order to catch other opportunities in niche or novelty markets linked to the increasing interest towards 'new varieties' (Padulosi et al. 1999). It is recognized the role that these processes play in broader territorial development strategies aimed at increasing local livelihood.

In developed countries, marketing strategies focusing on products whose properties build on specific genetic resources and the related interactions with the local environments are not new. As said above, many European 'typical products' present this peculiarity, which has been also recognized through geographical indications since the early 1990s (as the Protected Designation of Origin (PDO) and the Protected

\footnotetext{
${ }^{4}$ There are of course also the benefits stemming from the recognition of the ecosystem services provided by agro-biodiversity through market mechanisms. However, we refer here to the market valorisation of final biodiverse food products.
} 
Geographical Indication (PGI)). The market valorisation of these products has strongly contributed to their reintroduction in the local production-consumption systems and, more generally, in the food culture and in the eating practices. Again, also in these contexts, this has favoured processes of local development, thanks to the synergies created with other economic sectors.

The economic valorisation of products more specifically related to initiatives of biodiversity conservation - as underutilized or forgotten species - however represents a more recent opportunity. This is linked both to the new, increasing attention of public opinion to biodiversity among the other sustainability issues, and, in the case of food products, to the greater knowledge about nutritional aspects. The latter is supported by the spread of the findings of researches focusing on health benefits from underutilized products also out of the scientific environment (as, for example, in the case of properties of certain grain species/varieties to celiac disease). The opportunity to create new markets, based on these 'new products' and their multiple uses, is also at the base of the growing interest of public bodies and private economic actors, which results in multiple initiatives of promotion and valorisation (Padulosi et al., 1999).

\section{The role of the political framework}

Over the years, policy makers have recognized the importance of preserving and enhancing biodiversity. This has given rise to a variegated legislative framework that has contributed to shape the issue and has driven interventions, while at the same time defining the operating space of involved actors.

Political interventions have been promoted at international, regional, country and local levels. There have been three main categories of interventions: formal commitments to develop strategies to preserve biodiversity; measures to operationalise these strategies; legislative acts that allow the legal implementation of the strategies and operational measures. It is beyond the scope of this contribution to give a complete overview of the political interventions for biodiversity preservation and enhancement. However, some milestone cases, at the international and European level, are reported as examples of the political and legislative contributions to this matter and as source of insights on the most significant aspects at stake.

The first formal commitment to preserve and enhance biodiversity at the international level dates back to the early 1990s: the Convention on Biological Diversity (CBD), signed by 150 Governments at the 1992 Earth Summit in Rio de Janeiro. Through it, Governments aimed at combining the human need for food, health, shelter and other human needs with the preservation and enhancement of biodiversity. The Convention covers key aspects of biodiversity conservation and management, including natural resource management, and the social, cultural and economic values of biodiversity (Alho, 2008; Government of Ireland, 2008). 
To fulfil the obligations deriving from the CBD, in 1998 the European Commission has adopted the EC Biodiversity Conservation Strategy, through which the European Union (EU) commits to reduce the rate of biodiversity loss. The theme of biodiversity conservation returns in the EU Sustainable Development Strategy, adopted in 2001. In the frame of this strategy, the EU Member States commit to halt biodiversity loss by the year 2010. To this end, four Biodiversity Action Plans have been adopted at EU level. They foster cooperation between States and between States and civil society organisations as well as they set responsibilities for European Institutions. Moreover, they promote a cross-sectoral approach with actions planned in the field of agriculture, fisheries, economic and development cooperation, and conservation of natural resources (Government of Ireland, 2008).

A range of other multilateral environmental agreements were also established mainly during the 1970 s to protect biodiversity ${ }^{5}$. These measures attempt to ensure a coordinated process for addressing biodiversity loss. Their implementation is generally at national level through policies that, after valuation, address the sources of impacts on biodiversity. Valuation, underlying prioritization and setting of objectives, is to that end the crucial factor (OECD, 2008).

As far as it concerns the measures to operationalise the general commitments towards biodiversity, a relevant contribution comes from the European agricultural policies, which have over time included the maintenance and enhancement of agrobiodiversity amongst their main objectives. The various policies offer significant support to interventions addressed both to maintain or improve agro-biodiversity looking at final product diversification (food and other products) and to strengthen functional agro-biodiversity, referring to its capacity to provide eco-system services. Furthermore, the new program for rural development (Reg. 1305/2013) includes these objectives among the priorities of the forms of cooperation underlying the implementation of the European Innovation Partnership (COM (2012)79), stressing the importance of a multi-actor, integrated approach to the issue, aimed at actively involving all the stakeholders.

The support to biodiversity by the EU agricultural policy so focuses on two main areas of intervention. On the one hand, it addresses the conservation aspect, by funding interventions that are instrumental to the protection of local species/varieties; on the other hand, it pursues the way of economic valorisation of biodiversity, by supporting initiatives aimed at qualifying and defending on the market the specific quality products and at promoting services useful for the local communities.

Among the forms of market valorisation, the former tools are integrated with the

\footnotetext{
5 They encompass, for example, the Convention on International Trade in Endangered Species, the Ramsar Convention on Wetlands, the Convention on Protection of the World Cultural and Natural Heritage, and the Convention on the Conservation of European Wildlife and Natural Habitats.
} 
existing EU regulatory system of Geographical Indications aimed at protecting typical and traditional products (PDO and PGI). As said above, these measures build on the close link between agro-biodiversity and the biological and cultural specificities of regional products. Afterwards, the need to intervene not only on the farming system but rather on the whole value chain has led to consider the key role of the short supply chains, where favourable conditions for the appreciation of the product quality can develop (Naziri, 2009; Simoncini 2015).

As significant it appears the public support provided to the creation and valuation on the marketplace of environmental services, which is representing one of the most promising way to attach economic value to agro-biodiversity (OECD, 2008). Also in this case the adoption of an integrated approach is crucial. The growth of the environmental service supply in fact demands cooperation among different actors and related expertise (farmers and other enterprises, researchers, policy makers and administrators).

When moving to the regulatory framework, most of the acts concern the development, conservation and diffusion of seeds and plant varieties. The most significant aspect is here represented by the tendency to introduce recognitions and guarantees to the farmers' rights to produce, preserve and exchange seeds and the products, along to the breeders' property rights and the consumers' rights to nutritional safety. This move is meant to acknowledge farmers' contributions in developing and preserving seeds and plant varieties, which have become increasingly blatant with the diffusion of participatory crop improvement and market valorisation strategies.

In 1961, the International Convention for the Protection of New Varieties of Plants recognized the key role of plant breeders, creating the condition for the development of a system for plant variety protection working for registered varieties within the frame of conventional breeding approach. On the other hand, the more recent International Treaty on Plant Genetic Resource for Food and Agriculture (ITPGRFA) introduces some inputs to recognize farmers' rights to save, use, exchange seeds saved on farm and other propagating material. The Treaty encourages the contracting parties to promote policies, legal measures and strategies to acknowledge and encourage the contributions of farmers and traditional knowledge to maintain and reinforce the variety of genetic resources used for farming and food purposes.

The EU policies reflect the same dynamics. Some Directives, defined to regulate the production and diffusion of seeds, have been mostly focusing on guarantying varietal stability and safety. As an example, Dir. 2002/55/EC sets that only seeds varieties that prove to be distinct, stable and uniform can be registered in official catalogues and commercialised. Other Directives, such as Dir. 2009/145/EC, have been passed to open to the acceptance of traditional vegetable landraces that do not fit the above mentioned criteria but are relevant to combat genetic erosion. Furthermore, the EU Seed and Plants Reproductive Material Marketing Law has been going through a 
process of reform under the pressure of civil society organisations. They claim that this legislation still fails to adequate the EU regulation to the indications of the ITPGRFA since it does not safeguard the informal systems of production, conservation and exchange of reproductive material, which contribute to the biodiversity protection and in which farmers and their traditional knowledge play a crucial role. On the other hand, it has becoming increasingly evident how complex may be a change of the current system. It in fact demands not only to take into consideration the ethical issue of the recognition of farmers' contribution to the development of reproductive material, but also to face the questions of the legal responsibility for the submission and of the costs for the variety registration, the variety maintenance and basic seed production (Almekinders and Elings, 2001).

Together with these more recent tendencies in dealing with the issue of biodiversity management, it is finally worth mentioning how there is a growing recognition that effective policies for biodiversity conservation need to focus on the mitigation of socio-economic pressures on biodiversity, either directly or through modification of their underlying driving forces (Haberl et al., 2009). This is thought to be the most effective and durable option to reduce the rate of biodiversity loss. Also in this case, the fine-tuning of these measures demands an integrated research approach that integrate social sciences and economics with biodiversity research.

\section{A COMPREHENSIVE APPROACH TO PRESERVING AND ENHANCING AGRO-BIODIVERSITY: DIVERSIFOOD}

As showed in the previous sections, maintaining and enhancing agrobiodiversity is a complex process. It involves multiple actors, at the different stages of the food chain up to consumers; furthermore, it may also include other stakeholders, more in general interested in the promotion of territorial resources and food culture. The interactions amongst these actors around the meanings attached to agro-biodiversity, and the related learning processes and development of new practices that arise from them are central to agro-biodiversity management (Fig.1). They contribute to the definition, fine-tuning and running of the specific technical, organisational, cultural, social, economic and institutional components that, as seen above, are diversely involved in the various areas of agro-biodiversity management. The need to guarantee and optimise these interactions and to connect the different areas of action involved also highlights the importance of the adoption of proper approaches in promoting, analysing and supporting these processes.

The challenge of DIVERSIFOOD project is to take into consideration all this. The following sections explain the goals and the approach of this project as an exemplification of how research can contribute to define and implement comprehensive 
approaches to preserving and enhancing agro-biodiversity.

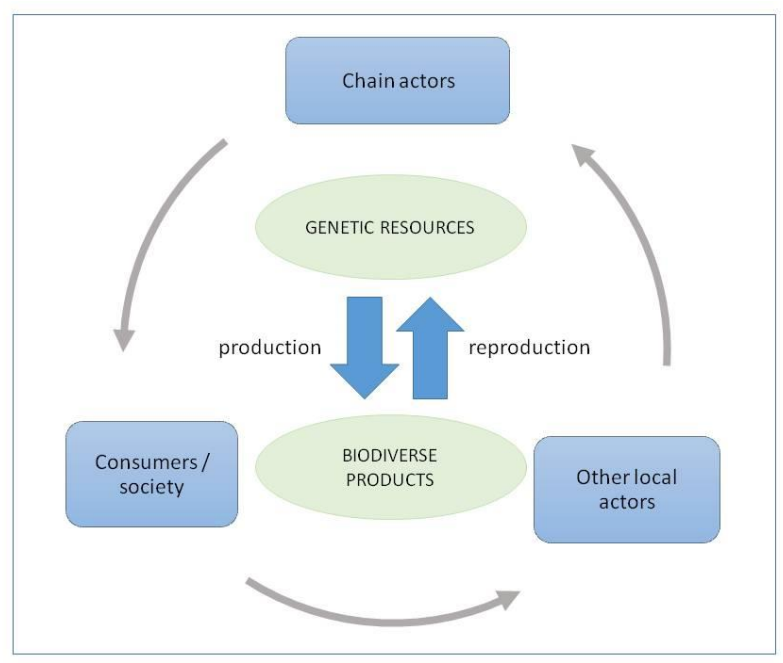

Fig. 1

The main objective of the project is to deepen the factors and processes of various nature that can support the reintroduction of biodiversity in cropping systems, improve its management and promote a social and economic valorisation of the related food products through proper communication and value chains.

Underlying this objective is the recognition of the urgent need to move towards farming systems able to recover and reproduce cultivated diversity, complementing the not fully effective efforts of ex-situ conservation (e.g. the gene banks) (Maxted et al., 2011; Bonneuil et al., 2012) but also overcoming the reductionist approach of the in-situ 'conservation'. In addition, the project builds on the belief of the importance of the availability of a range of varieties suitable to organic, low-input and marginal agriculture, able to cope with particular / more difficult environmental conditions (Wolfe et al., 2008). As important is improving the economic performance of biodiversity-oriented food system and strengthening the social awareness and consensus around biodiverse food values.

The DIVERSIFOOD project faces the challenge to improve the understanding and capacity to manage biodiversity-oriented food systems by adopting an integrated approach both in the identification of the relevant processes involved and in the way to explore them.

\section{The approach of DIVERSIFOOD}

The approach conceived for DIVESIFOOD follows two interrelated lines (Fig. 2). On one hands, the project investigates all the stages involved in the processes of 
enhancement of agro-biodiversity and valorisation of biodiverse products. These stages include: breeding of genetic material, farming activities, processing of row products, marketing and consumption of the final products. On the other hand, DIVERSIFOOD investigates a combination of aspects that intervene in the process of valorisation of biodiverse products in each of the listed stages. These aspects are: technictechnological, organisational, economic, social, cultural, political-legislative. In both levels of analysis, the project explores how the various actors interact in the management of agro-biodiversity values and how they develop new consistent practices.

The project relies on insights emerging from empirical research to produce conceptual and methodological reflections for scientists working in the field of agrobiodiversity preservation as well as recommendations for food chain practitioners, policy makers and civil society. To this end, its approach includes some space for theoretical reflections and dissemination activities.

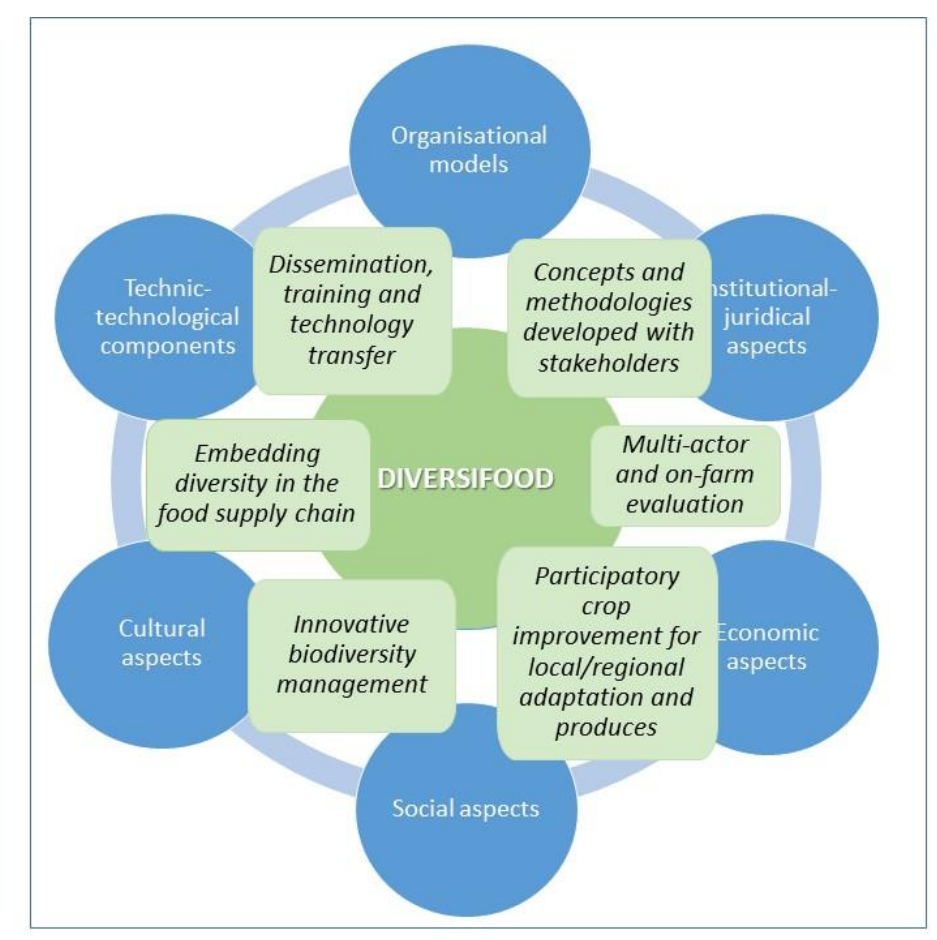

Fig. 2

A large part of the project activities is aimed at exploring the potential of underutilised genetic resources through multi-actor, on-farm evaluations. These activities involve experimentation on a number of agricultural and forestry cultivations aimed at testing different species and varieties in different agro-ecosystems, in the various European countries involved. The species and varieties examined belong to the local farming experience. However, their management is often to be improved, to respond both to the different environmental conditions and to the social changes in food 
requirements and uses (Fess et al., 2011). They are so evaluated for their agronomic properties and for the results in terms of nutritional and organoleptic quality of the final products, directly involving farmers and consumers. Central in this stage is the attention paid to several aspects, such as: local traditions in cropping and food practices; the particular needs of local farming contexts or of small scales of production affecting the technical approaches to the crops; the farmers' knowledge and expertise in managing biodiversity to be mobilized (in-situ management); the sustainability and profitability of the production systems; the creation of new food quality through combining old genetic resources, new techniques, a renewed food culture.

The effort to revalorise underutilised species and varieties is accompanied by activities of participatory crop improvement. These activities are aimed at identifying the breeding process and the crops that are suitable to the conditions of different regions in Europe. The aim is here to create new diversity in several important crops in Europe, but also, and above all, to develop new approaches to the care of agro-biodiversity by fine-tuning suitable methods and tools, designed for on-farm decentralised participatory breeding. This allows complementing the work of ex-situ conservation, in order to make available genetic resources more suitable to the current needs of production and consumption. The interaction amongst different sources of knowledge and expertise and amongst different fields of interests - by involving farmers, breeders, scientists, processors, users and final consumers - is here essential.

Other activities in DIVERSIFOOD focus on exploring the role social, institutional and political factors may play in enabling the participatory, multi-actors, on-farms approaches to genetic resources evaluation and crops improvement identified and tested during the project.

For many years a traditional, reductionist view considered the in-situ conservation of genetic resources for agriculture as a static function (the creation and running of a sort of open-air museum), not consistent with development goals (de Boef et al., 2013). Following more recent approaches (Louwaars et al., 2010; de Boef et al., 2010), the project advocates the role of 'on-farm management', seen in its potential of dynamic utilization of genetic resources, especially within a communitarian dimension (Thijssen et al., 2013). In this perspective, the agro-biodiversity is seen as a common good and its conservation and reproduction (both of them not excluding evolutionary dynamics) is faced by farmers collectively and through close interaction with other agents. This function is recognised and supported by society, represented in the local communities.

Focusing on the management of seeds as crucial factor of biodiversity management, the project looks at seed systems as complex adaptive systems spatially and socially distributed (Leclerc and Coppens, 2011), reflecting the immaterial diffusion of farmers' knowledge (Isaac et al., 2007). The community seed systems or seed localised networks become the space where to fine-tune the social and economic 
conditions needed to implement on-farm seed breeding and management. This includes identifying the key elements to strengthen community or network capacity as well as to raise society awareness about the values of these resources.

Regarding enabling factors, another relevant area of (action-)research aims at conducting an in-depth analysis of the role of the international legal framework of agrobiodiversity management, in order to increase the awareness of agents and policy world on its bottlenecks and possible improvements. As seen above, biodiversity management is affected by many national and international rules, laws and agreements dealing with access to genetic resources, the saving, reusing, exchanging and selling of seeds and other reproductive material, the improving of varieties and the conserving of landraces (from agro-biodiversity policies to seed laws, variety release procedures and intellectual property rights policies). In particular, the project focuses on the legal aspects that relate to on-farm management, aiming at highlighting problems and identifying ways to overcome them. To that end, it explores all the factors (of technical, organisational, economic, social and cultural nature) involved in the design of new solutions. Based on the findings of analyses and experimentations, at the end of the project the specific task aims at providing recommendations to policy makers, addressed to the creation of a new, enabling environment.

The enhancement of the agro-biodiversity through genetic resources evaluation, crops selection and other farming practices needs to integrate with a general acknowledgment and consensus by society and, more specifically, the appreciation of the final products on the market. Another area of activities in DIVERSIFOOD is so exploring the key elements underlying the building of a consistent valorisation strategy, aimed at strengthening and promoting the whole production-consumption system based on specific genetic resources, so guaranteeing their conservation and reproduction. According to the general approach, also the development of a valorisation strategy is considered as a multi-actor process, based on the role of the different actors involved from the breeding and farming stage to that of consumption of the final products. The interaction among these actors and the alignment of their attitudes and practices around the values embodied in the products are crucial aspects to explore. These aspects are important for the definition of the qualitative attributes of the final products, to which the genetic resources employed and their management in the fields as well as the agronomic techniques to produce the raw material and the processing modes are determinant. Furthermore, they underlie the economic and cultural valorisation of these attributes through marketing and communication practices, in the local and extra-local systems. The last are essential to further spread the knowledge of the value of biodiverse products and so contribute to the consolidation of the production systems. Also in this case, the project takes into account all the different dimensions - technical and organisational, economic, cultural and institutional - involved in the valorisation of the biodiverse products. 
Going back to methodology, it is evident that the project attaches great importance to the contribution that can come from the different actors involved in the construction of systems of production and consumption of biodiverse products. Their active involment is considered central for the evaluation of the performance of the various genetic resources on the field, of the economic aspects of seed management, of the properties of raw material for processing, of nutritional, healthy and organoleptic quality of the final products. As already emerged, this approach finds application through appropriate participatory methodologies in all the subtasks of the project.

At the basis of this participatory approach is the importance attached to the encounter amongst different forms of knowledge and expertise, considered potential sources of synergies, and to the development of a pool of new shared knowledge through the social learning that develop from interaction. More in general, the need to combine natural sciences, to catch the biological aspects of agro-biodiversity management, with social sciences, to take into account also the cultural and social determinants that intervene, sees the project engaged in experimenting and conceptualizing forms of inter-disciplinarity (Mathez-Stiefel et al., 2009; Nuijten et al., 2011; Johns et al., 2013). Together with finding effective modes of dialogue between academic and practitioners, between different chain agents or these and consumers, the integration amongst different disciplines represent the main methodological challenge of the project and one of the expected outcomes.

\section{SOME FINAL REMARKS}

There is a general social and political consensus on the importance of preserving and enhancing biodiversity. Nonetheless, several factors are causing a progressive loss of biological diversity. The process of agricultural intensification and specialisation that is the basis for the mainstream, industrial food system is identified as one of the threats to biodiversity. On the other hand, transitioning to sustainable farming is seen as a way to protect and enhance biodiversity, through the diversification of species and varieties in the production cycles as well as through the provision of agro-ecosystem services. In other words, preserving agro-biodiversity appears as a contribution to the broader goal of protecting and enhancing biodiversity.

There are however clear evidences of the complexity of the matter of agrobiodiversity management. This has firstly to do with the appreciation of the value of agro-biodiversity, which is crucial but inherently complex. There are in fact several values attached to agro-biodiversity. There are economic values as well as other values that may be decisive for agro-biodiversity management but are not always immediate and not easy to quantify in monetary terms, or subject to different interpretation by different stakeholders. The perception of agro-biodiversity values and their translation 
in coherent practices are, however, central to agro-biodiversity management. As illustrated by the study, these processes are related to other important aspects and processes, such as cultural and social dynamics, forms of stakeholders involvement, strategies of market valorisation of final products, role of the political frameworks within which strategies to maintain and enhance agro-biodiversity have to develop.

This study has presented the DIVERSIFOOD project as exemplification of the comprehensive approach that is needed to effectively preserve and enhance agrobiodiversity. The structure of the project expresses the effort to explore the processes underlying the re-shaping of practices according to the objective of agro-biodiversity enhancement in all the areas involved in tackling with agro-biodiversity, from the farming activities to commercialisation of the biodiverse food products. The need to take into consideration the different perspectives on the values and ways of preserving agro-biodiversity together with the social learning processes that lead to coherent practices underlies the adoption of participatory, multi-actors approaches to each of these stages. Breeder, farmers, processors, consumers and other actors of the food chains, scientists, civil society organisations and other relevant stakeholders are involved. Similarly, an inter-disciplinary approach, aimed at combining natural sciences and social sciences characterises the work of researchers. Looking at the mechanisms underlying and affecting the implementation of coherent practices, DIVERSIFOOD also investigates and raises awareness on the role that socio-cultural, legal and political frameworks may play in enabling socially recognised, participatory, community-based management of agro-biodiversity resources. This concerns all the areas of intervention analysed, but assumes special relevance in the specific case of on-farm management of seeds. This is the real and symbolic space in which the presence of different views, goals and approaches is more evident.

Finally, this contribution sheds light on the role that research may play in agrobiodiversity preservation. To be effective in this task, research projects shall look through a systemic approach at all the (environmental, technical, socio-cultural, economic, legal and political) aspects that intervene in the various areas of agrobiodiversity management. To that end, they shall involve both academics - from different disciplines - and practitioners and stakeholders -from different stages of the food chain and even beyond. Together, they should provide insights and recommendations on the many, connected entry points of agro-biodiversity enhancement.

\section{REFERENCES}

Alho CJR (2008) The value of biodiversity. Brazilian Journal of Biology 68:1115-1118. Almekinders C. J. M. and Elings A. (2001) Collaboration of farmers and breeders: Participatory crop improvement in perspective. Euphytica 122: 425-438. 
Ash, N., and Fazel A. (2007) Biodiversity. Global Environmental Outlook, 160-192. Association for Molecular Pathology et al. v. United States Patent and Trademark Oficce et al. 1:09-cv-04515-RWS (United States District Court, Southern District of New York, March 29, 2010).

Bonneuil, C., Goffaux R., Bonnin I., Montalent P., Hamon C., Balfourier F., and Goldringer I. (2012) A New Integrative Indicator to Assess Crop Genetic Diversity. Ecological Indicators 23 (December): 280-89. doi:10.1016/j.ecolind.2012.04.002 Brunori G., Rossi A., Malandrin V. (2011) Co-producing Transition: Innovation Processes in Farms Adhering to Solidarity-based Purchase Groups (GAS) in Tuscany, Italy., International Journal of Sociology of Agriculture and Food, 18 (1): 28-53. Ceccarelli S, Grando S (2007) Decentralized-participatory plant breeding: an example of demand driven research. Euphytica 155:349-360.

Clawson D.L. (1985) Harvest security and intraspecific diversity in traditional tropical agriculture Economic Botany, 39: 56-67.

Commission of the European Communities. Commission Directive providing for certain derogations, for acceptance of vegetable landraces and varieties which have been traditionally grown in particular localities and regions and are threatened by genetic erosion and of vegetable varieties with no intrinsic value for commercial crop production but developed for growing under particular conditions and for marketing of seed of those landraces and varieties. 2009/145/EC. Available at: http://eurlex.europa.eu/LexUriServ/LexUriServ.do?uri=OJ:L:2009:312:0044:0054:EN:PDF. Convention on Biological Diversity (CBD) (1992) United Nations, retrieved from www.cbd.int

Convention on International Trade in Endangered Species of Wild Fauna and Flora (CITES) (1973) Retrieved from https://www.cites.org/eng/disc/text.php

Convention on the Conservation of European Wildlife and Natural Habitats (1979). Available at http://www.coe.int/en/web/conventions/full-list/-/conventions/treaty/104 Council of the European Union. Council Directive on the marketing of vegetable seed. 2002/55/EC. Available at http://eur-lex.europa.eu/legalcontent/EN/TXT/PDF/?uri=CELEX:32002L0055\&from=en

De Boef, W.S., Dempewolf H., Byakweli J.M., and Engels J.M.M.. (2010) Integrating Genetic Resource Conservation and Sustainable Development into Strategies to Increase the Robustness of Seed Systems. Journal of Sustainable Agriculture 34 (5): 504-31.

De Boef, W.S., Subedi A., Peroni N., Thijssen M. and O'Keeffe E., eds. (2013) Community Biodiversity Management: Promoting Resilience and the Conservation of Plant Genetic Resources. Issues in Agricultural Biodiversity. London: Routledge, Taylor \& Francis Group. http://www.routledge.com/books/details/978041550 2207/. European Commission (EC) 1998. EC Biodiversity Conservation Strategy (ECBS), retrieved from 
http://ec.europa.eu/environment/nature/biodiversity/strategy/index_en.htm

European Union (EU) 2001. Sustainable Development Strategy (SDS), retrieved from http://eur-lex.europa.eu/legal-content/EN/TXT/?uri=URISERV\%3Al28117

Farnworth C.R. and Jiggins J. (2003) Participatory Plant Breeding and Gender Analysis. PPB Monograph n. 4.

Fess, T.L., Kotcon, J.B., and Benedito, V.A. (2011) Crop breeding for low input agriculture: a sustainable response to feed a growing world population. Sustainability, 3, 1742-1772.

Food and Agriculture Organization (FAO). The International treaty on Plant Genetic Resources for Food and Agriculture. Available at:

http://ftp.fao.org/docrep/fao/011/i0510e/i0510e.pdf

Government of Ireland (2008) The Economic and Social Aspects of Biodiversity.

Benefits and costs of biodiversity in Ireland. The Stationary Office, Dublin.

Gruère G., Smale M., Giuliani A. (2006) Marketing Underutilized Species for the

Benefit of the Poor: A Conceptual Framework. IFPRI, Washington, DC (EPT

Discussion Paper 154)

Haberl, H., Gaube, V., Díaz-Delgado, R., Krauze, K., Neuner, A., Peterseil, J. Plutzar, C., Singh, S.J., Vadineanu, A. (2009). Towards an integrated model of socioeconomic biodiversity drivers, pressures and impacts. A feasibility study based on three European long-term socio-ecological research platforms. Ecological Economics (2009)

Hardon, J. (1995) Participatory Plant Breeding. The Outcome of a Workshop on Participatory Plant Breeding, 26-29 July 1995. Plant Genetic Resources No. 3. IPGRI, Rome.

International Convention for the Protection of New Varieties of Plants (1961) Available at http://www.wipo.int/wipolex/en/other_treaties/details.jsp?treaty_id=27

Johns T., Eyzaguirre P.B. (2006) Linking biodiversity, diet and health in policy and practice. In Symposium on Wild-gathered plants: basic nutrition, health and survival Proceedings of the Nutrition Society, 65: 182-189.

Joshi, A. and J. R. Witcombe (1996) Farmer Participatory Crop Improvement II.

Participatory Varietal Selection, A Case Study in India, Experimental Agriculture 32:

461-77.

Krucken L. (2005) Design and the valorisation of agricultural biodiversity products - a case study. Proceedings of the 6th international conference of the European Academy of Design. University of the Arts of Bremen, Bremen.

Laverty M.F. and E.J. Sterling E.J. (2003) Why is Biodiversity Important? Center for Biodiversity and Conservation of the American Museum of Natural History Leclerc, C. and Coppens d'Eeckenbrugge G (2011) Social Organization of Crop Genetic Diversity. The G $\times$ E $\times$ S Interaction Model. Diversity 4 (4): 1-32. doi:10.3390/d4010001.

Louwaars, N., Le Coënt P, and Osborn T (2010) Seed Systems and Plant Genetic 
Resources for Food and Agriculture. Thematic background study for the Second Report on the State of the World's Plant Genetic Resources for Food and Agriculture. Rome: FAO.

http://www.fao.org/fileadmin/templates/agphome/documents/PGR/SoW2/tbs_Seed_Sys tems_081209.pdf.

Mathez-Stiefel S.L., Gianella M. C., Rist S. (2009) Valorisation of Agrobiodiversity products and strengthening of local identities in the Peruvian Andes: Experiences from the BioAndes Programme. Colloque "Localiser Les Produits".

Maxted, N., Z.I. Akparov, M. Aronsson, A. Asdal, A. Avagyan, B. Bartha, D. Benedikova, et al. (2012) Current and Future Threats and Opportunities Facing European Crop Wild Relatives and Landrace Diversity. In: Agrobiodiversity Conservation: Securing the diversity of crop wild relatives and landraces, edited by $\mathrm{N}$ Maxted, M.M. Iriondo \& M.M.A.Pinheiro de Carvalho, 333-53. CABI publ. Mayes S., Massawe F.J., Alderson P.G., Roberts J.A., Azam-Ali S.N., and Hermann M. (2011) The potential for underutilized crops to improve security of food production. Journal of Experimental Botany doi:10.1093/jxb/err396

Morris ML, Bellon MR (2004) Participatory plant breeding research: opportunities and challenges for the international crop improvement system. Euphytica 136:21-35 Naziri, D. (2009) Direct Sale as a Means for Promoting the Sustainable Use of Plant Genetic Resources: The Case of the Tuscany Region. Journal of Agriculture and Environment for International Development, n. 1/2.

OECD (2002) Handbook of Biodiversity Valuation. A guide for policy makers. Padulosi, S., Eyzaquirre, P. \& Hodgkin, T. (1999). Challenges and strategies in promoting conservation and use of neglected and underutilized crop species. In: J. Janick (editor). Perspectives on new crops and new uses. ASHS Press, Alexandria, Virginia, USA.

Padulosi, S., J. Thompson, and P. Rudebjer. (2013) Fighting Poverty, Hunger and Malnutrition with Neglected and Underutilized Species (NUS): Needs, Challenges and the Way Forward. Bioversity International, Rome, IT.

Pimentel D., Stachow U., Takacs D.A., Brubaker H.W., Dumas A.R., Meaney J. J., O’Neil J.A.S., Onsi D.E., Corzilius D.B. (1992) Conserving Biological Diversity in Agricultural/Forestry Systems. Bioscience, 42(5): 354-362.

Ramsar Convention on Wetlands (1975) Available at http://www.ramsar.org/about/theramsar-convention-and-its-mission

Simoncini R. (2015) Introducing territorial and historical contexts and critical thresholds in the analysis of conservation of agro-biodiversity by Alternative Food Networks in Tuscany, Italy. Land Use Policy, 42, 355-366.

Thijssen, M, De Boef WS, Subedi, A, Peroni N, and O'Keeffe E. (2013) General Introduction. In Community Biodiversity Management: Promoting Resilience and the Conservation of Plant Genetic Resources , 3-10. Issues in Agricultural Biodiversity. 
London: Routledge, Taylor \& Francis Group. http:

//www.routledge.com/books/details/9780415502207/.

Tripp, R., (1997) The structure of the National Seed Systems. In: R. Tripp (Ed.), New Seeds and Old Laws. Regulatory Reform and the Diversification of National Seed Systems, pp. 14-42. IT Publications, London.

UNESCO (1972) Convention Concerning the Protection of the World Cultural and Natural Heritage. Available at http://whc.unesco.org/en/conventiontext/.

Van Noordwijk M, Spek LY, De Willingen P (1994) Proximal root diameters as predictors of total root system size for fractal branching models. I. Theory. Plant and Soil 164: 107-118.

Will, M. (2008) Promoting Value Chains of Neglected and Underutilised Species for Pro-Poor Growth and Biodiversity Conservation. Guidelines and Good Practices, Rome: Global Facilitation Unit for Underutilised Species. 